\title{
Long-term effects of azathioprine in rheumatoid arthritis*
}

\author{
M B UROWITZ, H A SMYTHE. T ABLE, C S NORMAN AND C TRAVIS \\ From the Rheumatic Disease Unit, Wellesley Hospital, 160 Wellesley Street E, Toronto, Ontario, Canada \\ M4Y $1 J 3$.
}

SUMMARY Efficacy and safety of azathioprine in 'high' and 'low' dose regimens in rheumatoid arthritis (RA), both in short-term studies and in follow-up over $\mathbf{4 0}$ months, have previously been shown. In the present report, 36 patients with RA treated with azathioprine (group I) and 49 age-matched patients with RA (group II), were studied to detect potential early markers of malignancy.

Chest $x$-rays were similar in both groups. One patient in group I had a positive PAP smear and was subsequently found to have uterine carcinoma. Alpha-fetoprotein was positive in one patient in group I and none in group II. CEA was negative in all patients in group I, but positive in seven in group II. On chromosomal analysis group I showed a greater frequency of breakage. Group I showed lower serum folates and a highly significant number of megaloblastic features in marrow aspirates.

In group I seven tumours, three being malignant, occurred while taking azathioprine, and in group II six tumours, one malignant, were identified $(p=0 \cdot 17)$.

The apparent increased risk of malignancy previously suggested by others warrants further studies with larger populations and over a continuous longer period.

Azathioprine has been shown to be an effective agent in the treatment of active rheumatoid arthritis (RA). ${ }^{38124143224}$ The long-term side-effects of this purine analogue, especially the potential for the induction of neoplastic change, have been described only sporadically in patients with RA. In 1976, two patients with seropositive RA, treated with both azathioprine and alkylating agents and who developed leukaemia, were reported from this unit. ${ }^{196}$ This prompted us to examine a group of patients with RA on azathioprine, with respect to the incidence of neoplasms, to try to detect any specific

-This work was supported by the Canadian Arthritis Society, 920 Yonge Street, Ste 420, Toronto, Ontario, Canada. Grant Number: 7-195-74. clinical or laboratory markers in patients with neoplastic change.

\section{Method}

Thirty-six patients with classical or definite RA by American Rheumatism Association (ARA) criteria ${ }^{186}$ receiving azathioprine were chosen to take part in this in-patient study.

Forty-nine age and sex matched patients, with classic or definite RA, who volunteered for a "cancer check-up', were chosen from our in-patient and outpatient population as controls. These patients were on standard anti-inflammatory and disease suppressant (gold, chloroquine, penicillamine) medications; none had ever taken azathioprine or any cytotoxic agents. A medical history was obtained from each patient and a complete physical examination was performed. Total active joint count, grip strength ${ }^{191}$ and functional class were recorded.

Laboratory tests performed included: haemoglobin, white blood cell (WBC) count and differential, platelet count, erythrocyte sedimentation rate (ESR) by the Westergren method, latex fixation test, ${ }^{201}$ SGOT, alkaline phosphatase, protein electrophoresis, serum iron and total iron binding capacity. Serum folate determinations before July 1977 were performed using a microbiological assay. ${ }^{36} 204$ After July 1977, a radiodilution method was adopted (Amersham Folate Radioassay Kit). Serum $B_{12}$ was performed by a radiodilution method. ${ }^{183}$ Alpha-fetoprotein was measured by immunodiffusion in agar gel. ${ }^{164}$ Carcino-embryonic antigen (CEA) was detected by radioimmunoassay (Hoffman-LaRoche Kit). Urine and sputum cytology, when obtainable, was studied on each patient.

Radiological examinations included chest $x$-rays on all patients, mammography on each female and barium contrast studies, when indicated. All patients were examined by a dermatologist with attention to neoplastic changes of the skin. All women were 
examined by a gynaecologist and cervical and vaginal smears were taken.

Bone marrow aspiration was performed on all patients receiving azathioprine and the samples examined by one of us (CSN). Marrow chromosomal analyses ${ }^{153} 195215$ were performed on 25 patients of the 36 in the azathioprine group and in 11 of the 49 controls.

Statistical analyses of the results were carried out using the Fisher's exact test and the $\chi^{2}$ test. Significance testing was carried out at the $5 \%$ level.

\section{Results}

Group I (azathioprine treated) consisted of 36 patients, eight males and 28 females. Group II (control) consisted of 49 patients, 13 male and 36 female. There was no significant difference between the groups with respect to sex. The mean age was significantly higher in group I than in group II ( 57.8 years vs 51.4 years). Group I had a slightly longer disease duration (15.3 years vs 11.9 years) (table 1 ).

Group I had taken azathioprine for a mean duration of 38.5 months. The mean dose of drug for the group at assessment was $1.08 \mathrm{mg} / \mathrm{kg} /$ day. This was less than the mean dose at initiation of azathioprine treatment $(1.33 \mathrm{mg} / \mathrm{kg} / \mathrm{day})$. When the groups were compared with respect to concomitant medications within the three months before assessment, more group I patients had taken chloroquine and for a longer duration than patients in group II. There was a higher frequency of gold and penicillamine treatment in the control group at the time of assessment. Eleven patients in group I were taking low-dose prednisone, while only two patients in group II were on prednisone. Four patients in the azathioprine treated group had had intra-articular injections of their knees with radioactive gold; three patients had had both knees injected since the diagnosis of RA. One patient in group II had had a knee injected with radioactive yttrium and one had had a knee injected with radioactive gold. All patients had had intra-articular steroids at some time in their course. None was taking phenylbutazone.

TABLE 1 Study population

\begin{tabular}{llll}
\hline & $\begin{array}{l}\text { Group I; } \\
\text { azathioprine } \\
\text { treated }\end{array}$ & $\begin{array}{l}\text { Group II; } \\
\text { control }\end{array}$ & Significance \\
\hline No of patients & 36 & 49 & \\
$\quad$ Male/female & $8 / 28$ & $13 / 36$ & \\
Age (yr) & 57.8 & 51.4 & $\mathrm{p}=0.05$ \\
$\begin{array}{l}\text { Disease duration (yr) } \\
\text { Duration of }\end{array}$ & 15.3 & 11.9 & $\mathrm{p}=0.22$ \\
$\quad$ azathioprine (mth) & 38.5 & & \\
Dose of azathioprine & $1.08 \mathrm{mg} / \mathrm{kg} / \mathrm{day}$ & & \\
\hline
\end{tabular}

Age, duration and dose are given as means.
TABLE 2 Clinical features

\begin{tabular}{|c|c|c|c|}
\hline & $\begin{array}{l}\text { Azathioprine } \\
\text { treated (36) }\end{array}$ & $\begin{array}{l}\text { Control } \\
\text { (49) }\end{array}$ & Significance \\
\hline Active joint count & $11 \cdot 3$ & $16 \cdot 2$ & $p=0.02$ \\
\hline Grip strength (mmHg) & 150 & 126 & $p=0.12$ \\
\hline $\operatorname{ESR}(\mathrm{mm} / \mathrm{h})$ & $51 \cdot 3$ & $23 \cdot 3$ & $p=0.000002$ \\
\hline $\begin{array}{l}\text { Extra-articular } \\
\text { features/patient }\end{array}$ & $\begin{array}{l}1 \cdot 1 \\
4 \cdot 12\end{array}$ & $\begin{array}{l}0.9 \\
4 \cdot 01\end{array}$ & \\
\hline
\end{tabular}

*Tube numbers: tube $1=$ titre $1 / 40$, thereafter doubling dilutions.

TABLE 3 Laboratory features: haematology

\begin{tabular}{llll}
\hline & $\begin{array}{l}\text { Azathioprine } \\
\text { treated (36) }\end{array}$ & $\begin{array}{l}\text { Control } \\
\text { (49) }\end{array}$ & Significance \\
\hline Haemoglobin $(\mathrm{g} / \mathrm{dl})$ & 12.76 & 12.77 & $\mathrm{p}=0.13$ \\
WBC $\left(\mathrm{mm}^{3}\right)$ & 5591 & 7311 & $\mathrm{p}=0.002$ \\
Polymorphs $\left(\mathrm{mm}^{3}\right)$ & 3931 & 5225 & $\mathrm{p}=0.23$ \\
Lymphocytes $\left(\mathrm{mm}^{3}\right)$ & 1181 & 1720 & $\mathrm{p}=0.15$ \\
Platelets $\left(\mathrm{mm}^{3}\right)$ & 287972 & 368827 & $\mathrm{p}=0.08$ \\
\hline
\end{tabular}

Clinically, both groups were comparable as to grip strength, extra-articular manifestations and latex titre (table 2). They differed significantly in the joint count, with group II having a greater number of active joints (16.2 vs 11.3$)$, and ESR, with group II having a lower ESR $(51 \cdot 3$ vs $23 \cdot 3)$. There were no marked differences in fertility, hormone treatment and history of cigarette smoking between the groups.

Both groups were comparable in terms of SGOT, alkaline phosphatase and protein electrophoresis results. The groups did not differ with respect to iron studies, haemoglobin and platelet, neutrophil and lymphocyte counts. The total white blood cell count was significantly lower in the azathioprine treated group (table 3 ).

Chest $x$-rays were similar in both groups. Inflammatory and fibrotic abnormalities were seen in 15 patients in group I and nine patients in group II. There were no suspicious lesions seen in either group. Mammography showed a comparable number of benign lesions, that is, fibrosis, generalised calcifications and/or dysplasia. No masses or signs of malignancy were seen except for one suspicious lesion in a woman in group I and three in group II. These women are being followed carefully and, thus far, show no evidence of malignancy.

Cervical smears (Papanicolaou) on all women were negative except for one patient in group I who subsequently was found to have adenocarcinoma of the uterus on curettage. Urine cytology was abnormal in four patients in group I and one patient in group II, showing dyskaryotic changes. Those patients demonstrating abnormal urine cytology have been followed and none has shown development of urinary tract neoplasms.

Alpha-fetoprotein testing was positive in one patient in group I, with no evidence of associated 
malignancy. All patients in group II were negative. CEA levels were negative in 15 patients tested in group I. In group II, 35 patients were tested and seven were positive. These seven people have been followed and show no evidence of malignancy. Family histories revealed a higher incidence of patients in group I who had first degree family members with diagnosed malignancies ( 15 vs six).

The occurrence of tumours in both groups was examined. In group I, seven patients had eight neoplasms, one of which, a thyroid adenoma, occurred before azathioprine was started. Hence, seven patients developed seven neoplasms after commencing azathioprine. Of these seven tumours three were malignant (table 4). For the seven patients the mean exposure to azathioprine was 1.6 years before diagnosis of their neoplasms. Four patients had a positive family history of malignancy.

In group II, five patients had six neoplasms in all, one of which was malignant. The tumours were: thyroid adenoma, lipoma, neurofibroma, two fibroids and a diffuse histiocytic lymphoma. None of these five patients had a positive family history of malignancy.

In terms of malignant and potentially malignant lesions, group I had three such tumours (two adenocarcinomas of the uterus, one carcinoma-insitu of the cervix) and group II had one diffuse histiocytic lymphoma. This difference did not reach statistical significance $(p=0.1728)$. The clinical and laboratory results of those patients with malignancies in group I did not differ significantly from group I as a whole.

Examination of marrow aspirates revealed a highly significant number of megaloblastic features in 28 of 36 patients studied in group $\mathrm{I}$, whereas only one out of 19 patients studied in group II showed such a change (table 5). Serum $B_{12}$ levels were similar in both groups, but serum folate levels, by both micro- biological and radiodilution assay, were significantly lower in group $\mathrm{I}$.

Analysis of marrow chromosomes performed in 25 of the 36 patients in group I and 11 of the 49 in group II showed striking differences in aberration index, percentage of cells with aberrations and aberration

TABLE 5 Laboratory features: erythropoietic factors

\begin{tabular}{llll}
\hline & $\begin{array}{l}\text { Azathioprine } \\
\text { treated (36) }\end{array}$ & $\begin{array}{l}\text { Control } \\
\text { (49) }\end{array}$ & Significance \\
\hline Marrow-megaloblastic & $28 / 36$ & $1 / 19$ & $\mathrm{p}<0.005$ \\
$\mathrm{~B}_{12}$ (ng/l) & 421 & 383 & $\mathrm{p}=0.63$ \\
Serum folate (ng/l) & 4.89 & 6.75 & $\mathrm{p}<0.025$ \\
*Serum folate (ng/l) & 4.76 & 7.05 & $\mathrm{p}=0.02$ \\
\hline
\end{tabular}

*Radiodilution.

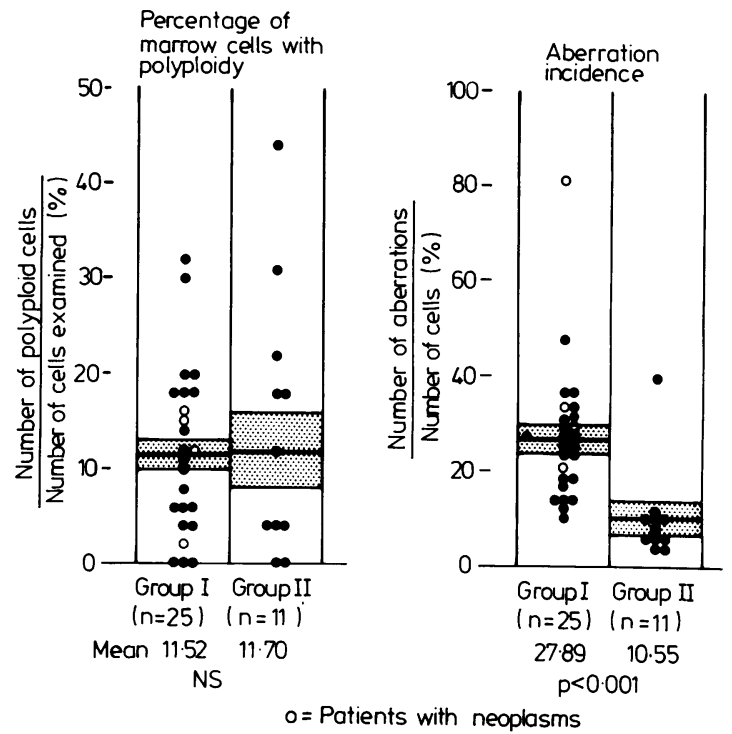

FIG 1 Marrow chromosomal analysis on 25 patients in group I and 11 in group II showing similar percentage of cells with polyploidy but a higher aberration incidence in group I.

TABLE 4 Neoplasms in azathioprine treated patients

\begin{tabular}{|c|c|c|c|c|c|c|c|}
\hline Patient & Sex & $\begin{array}{l}\text { Age } \\
(y r)\end{array}$ & $\begin{array}{l}\text { Azathioprine } \\
\text { dose } \\
\text { (mg/kg/day) }\end{array}$ & $\begin{array}{l}\text { Duration of } \\
\text { azathioprine } \\
\text { (mth) }\end{array}$ & $\begin{array}{l}\text { Other } \\
\text { medications } \\
\text { at diagnosis } \\
\text { of cancer }\end{array}$ & Tumour & $\begin{array}{l}\text { Family } \\
\text { history }\end{array}$ \\
\hline JA & $\mathrm{F}$ & 44 & $1 \cdot 8$ & 34 & $\begin{array}{l}\text { Prednisone } \\
\text { Chloroquine }\end{array}$ & Ca-in-situ & + \\
\hline $\mathrm{PMcM}^{*}$ & $\mathbf{F}$ & 54 & $0 \cdot 85$ & 34 & Prednisone & $\begin{array}{c}\text { Adeno Ca } \\
\text { uterus }\end{array}$ & - \\
\hline DP & $\mathbf{F}$ & 47 & $1 \cdot 0$ & 12 & - & $\begin{array}{c}\text { Adeno Ca } \\
\text { uterus }\end{array}$ & + \\
\hline JD & $\mathrm{F}$ & 50 & $1 \cdot 38$ & 20 & - & Haemangioma & + \\
\hline DD & $\mathrm{F}$ & 52 & $1 \cdot 16$ & 11 & - & $\begin{array}{l}\text { Benign liver } \\
\text { cyst }\end{array}$ & - \\
\hline MT & $\mathrm{F}$ & 70 & $2 \cdot 02$ & 12 & - & Anal polyp & - \\
\hline JH & $\mathrm{F}$ & 47 & $0 \cdot 80$ & 12 & - & $\begin{array}{l}\text { Fibroadenoma } \\
\text { breast }\end{array}$ & + \\
\hline
\end{tabular}




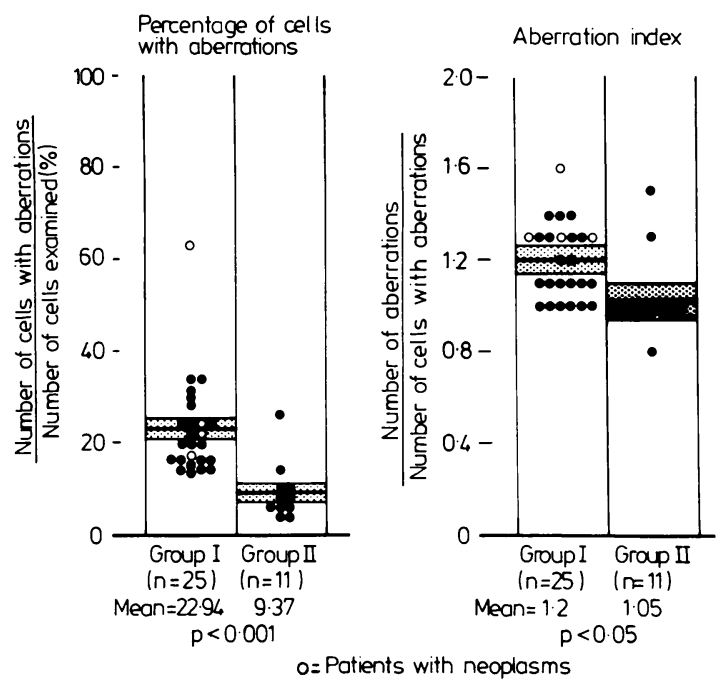

FIG 2 Marrow chromosomal analysis on 25 patients in group I and 11 in group II showing a greater percentage of cells with aberrations and a higher aberration index in group $I$.

incidence. The azathioprine treated group I showed more abnormal patterns (figs 1,2) in three of the four chromosomal variables measured. (Normal value in our laboratory for the aberration incidence is $10 \%$ or less.)

Four of the patients with neoplasms in group I showed a greater number of chromosomal abnormalities than the other 21 studied in the group. Two of these patients had benign and two malignant neoplasms. However, the two patients with malignancies differed from the remainder of group I in only one of the variables, the aberration index.

\section{Discussion}

The use of azathioprine in severely active RA, refractory to standard disease suppressants, has been shown to be effective in several studies, ${ }^{3 \times}{ }^{124}{ }^{143}{ }^{224}$ but potential neoplastic effects have remained a serious concern. There have been several case reports of malignancy in patients with RA on azathioprine alone, or in combination with other cytotoxics, ${ }^{23279125176177196}$ with a striking frequency of acute myelogenous leukaemia, occurring predominantly in males. ${ }^{79} 196$

Azathioprine was first shown to be associated with an increased incidence of malignancies when used in combination with prednisone in the management of organ transplants. ${ }^{175}{ }^{176}$ Although the reported incidence of this complication may be higher because of the possible overlapping incidence of malignancy during chronic renal failure, ${ }^{198}$ there is no doubt that organ transplant patients maintained on chronic immunosuppressive treatment have a significantly increased risk of developing de novo cancers within the first few years of transplantation. Almost all such patients received azathioprine and prednisone, as well as other immunosuppressive medications in several cases. This phenomenon has been variously explained by: the chronic presence of, and stimulation by, foreign transplanted antigen; immunosuppression sufficient to allow survival of spontaneous host tumours; and increased susceptibility to viral oncogenesis; or direct oncogenic effect by the immunosuppressive agent.

In more recent years, azathioprine has been used in many non-malignant conditions characterised as being of 'immunological' origin. Although Sharon et al's series of SLE patients ${ }^{198}$ and Worthington's observations (cited in Skinner and Schwartz ${ }^{202}$ ) of only one malignancy per 3000 such patients have been used to deny an increased incidence of neoplasms in patients treated with immunosuppressive agents, over 30 cases of malignancies have been reported in this group treated by azathioprine alone, or in combination with other cytotoxic agents. Many of these cases admittedly have a tenuous relationship to the drug in question. ${ }^{8} 293261749011 \times 1251271341411461.57$

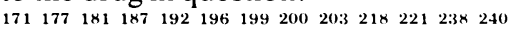

We have compared 36 patients with RA taking long-term azathioprine therapy (group I) with 49 age and sex matched patients not taking this medication (group II). The groups were similar in clinical and laboratory features except for a higher age and lower WBC counts in the azathioprine group, as previously reported. ${ }^{95} 225$

The outstanding finding was the demonstration of seven tumours in group I while they were taking azathioprine, three of which were malignant or premalignant. This was compared to five benign and one malignant tumour in group II. Of the 36 azathioprine treated patients in this study, only women developed neoplasms. The three malignant lesions were located in the genitourinary tract, a common site for neoplastic change in the elderly female, and the benign lesions were found in the skin, liver, breast, bowel and uterus. There was one malignant neoplasm identified in control group II, a diffuse histiocytic lymphoma. Previously reported prevalence rates of malignancy in RA have been either comparable to non-rheumatoid groups, ${ }^{166}$ or unexpectedly low $(0.6 \%) .{ }^{126}$ The finding of three malignancies among 36 azathioprine treated patients as compared with one among the 49 controls is not statistically significant $(p=0 \cdot 1728)$. Furthermore, statistics from the Ontario Cancer Research Foundation suggest that the expected incidence of malignan- 


\section{Suppl p 22 Annals of the Rheumatic Diseases}

cies over a three-year period in age matched females should be less than one case per 28 women $(0.75$ cases/28 women) (Ontario Cancer Treatment and Research Foundation). ${ }^{162}$ This is not significantly less than our finding of three cases per 28 women.

Significantly the diagnosis of neoplastic change in group I occurred early in the course of their treatment, within a mean of 1.6 years from the initiation of therapy, as compared to a mean duration of 3.5 years of azathioprine treatment in group I as a whole. It is of interest that an additional male patient in group I developed a malignant lymphoma while still taking azathioprine, one year after his assessment in this study, and two patients, already reported from this unit previously, developed acute leukaemia. No controls for these patients were available. On the other hand, the four patients with benign lesions continued to take azathioprine for a further mean period of 20 months and have suffered no malignant transformation nor further neoplasms. Of the three patients with malignancies, two have elected to continue azathioprine after treatment of their neoplasms and have suffered no recurrence nor further primary malignancies. This pattern would imply that a premalignant lesion may be present when azathioprine is initiated, and with immunosuppression the malignancy may manifest itself relatively early during the course of treatment. Carcinomas of the cervix are a common de novo cancer in renal transplant patients occurring in the first years after transplantation. ${ }^{176}$ Cervical dysplasia occurring as soon as 12 days after initiation of azathioprine therapy has been reported. ${ }^{85}$

Marrow chromosomal analysis has been shown to be a more effective means of determining cytogenic effects of agents than leucocyte chromosomal analysis. ${ }^{104} 144$ We performed marrow chromosomal analysis and found an increased number of abnormalities in the azathioprine treated group despite the fact that the mean dose of azathioprine used was 1.08 $\mathrm{mg} / \mathrm{kg} /$ day, a low dose regimen. Nevertheless, chromosomal changes were significantly abnormal, but the number of abnormalities could be correlated neither to the dose nor to the duration of azathioprine treatment, a finding previously reported ${ }^{105}$ Our results confirm previous reports of the clastogenic effect of azathioprine on chromosomes in nonmalignant disease. These changes have been reported to return to normal on discontinuation of the drug. ${ }^{95}{ }^{105}$ However, there was a marked degree of overlap between results in group I and group II. As well, this overlap was apparent when comparing results of those patients in group I with tumours and the remainder of group I. Although those with tumours had greater chromosomal abnormalities as a group, other subjects in group I, as well as in group II, had equally abnormal analyses when looked at individually (figs 1,2 ). Thus, the chromosomal analysis alone could not identify those individual patients with neoplasms. The development of tumours may reflect an increased susceptibility to the oncogenic potential of azathioprine in certain patients, a susceptibility possibly marked by a positive family history for malignancy (table 4).

Originally claimed to be a marker of bowel carcinoma, the CEA has now proven to be much less specific. None of the patients in the azathioprinetreated group had increased levels of CEA. Of interest, is the fact that seven of the control group had significant levels without evidence of any neoplasms. This finding of raised CEA levels in seropositive RA has been previously reported. ${ }^{222} 223$

Alpha-fetoprotein is another oncofetal antigen previously reported to be a potential marker for hepatic carcinoma. ${ }^{4}$ We detected this antigen in only one patient in group I, who proved to have no evidence of an associated malignancy. All patients in group II were negative for alpha-fetoprotein.

The problem of therapy with azathioprine in RA and the increasing incidence of neoplastic disease resulting from such treatment is a serious consideration, but to date no registry has been organised to gather and analyse such cases in a similar manner to that performed for organ transplant malignancies. Without such an organisation, meaningful statistics and conclusions will inevitably be delayed. We conclude that the apparent increased risk, as demoristrated in this study, warrants further studies with larger populations and over a continuous longer period. 